\title{
LA CONCIENCIA MORAL Y LOS VALORES
}

En busca de un punto de apoyo firme para la clucidación del problema moral propongo un retorno a la conciencia y a sus modos intencionales, es decir, un retorno a esa realidad intimamente sentida y vivida donde, de una manera u otra, tiene lugar toda experiencia humana.

Cualquiera sea, en efecto, la naturaleza de la experiencia y de los objetos que en ella nos son dados, o con los cuales entramos en relación, es en la conciencia donde se verifica, en un aquí y un ahora, en una determinada situación concreta. Más aún: en un sentido general, la experiencia no es en definitiva otra cosa que el propio actuar de la conciencia, el fluir constante de las vivencias que la constituyen con sus particulares contenidos objetivos y sus diversos modos de referirse a éstos. No existe experiencia alguna fuera de la conciencia, ni cabe imaginar una conciencia que no sea conciencia de algo, un estar en relación con las cosas y, por lo tanto, una forma de experiencia.

Esta conciencia que tomo como punto de partida no es ningún ente metafísico, el resultado de un esfuerzo especulativo que busca desentrañar su real o supuesto ser en sí, sino la conciencia en acto, el inmediato referirse de un sujeto a algo, como su objeto, en la percepción, en el juicio, en el sentir; en el querer. Es la conciencia individual, viva, concreta, tal como nos es dada en la realidad de la exṕeriencia propia y ajena.

Como toda experiencia, también la experiencia moral se cumple en la conciencia, es decir, en lo que solemos llamar la conciencia moral, cualquiera sea el modo como en definitiva se la entiendà. La conciencia moral presupone la conciencia plena, centro activo de toda experiencia posible, cuyos modos intencionales fundamentan las diversas especificaciones de la conciencia teorética, religiosa, moral, artística, económica, social. No es que en el sujeto coexistan, independientes entre sí, muchas conciencias. La conciencia es una, pero se revela o se manifiesta de diversas manerás en su relación con los objetos a los cuales se refiere, incluso consigo misma. La actitud puramente teórica de nuestro espíritu, por la cual la conciencia se aplica a la aprehensión del ser de las cosas, es distinta de la volitiva y de la emocional; la experiencia religiosa, por su sentido y su intencionalidad, es ajena en su esencia a la experiencia moral, artística o científica, pero todas pertenecen a una misma conciencia que despliega sus posibilidades en una multiplicidad de formas que se mantienen estrechamente enlazadas y entrecruzadas en todo momento.

La unidad de la conciencia es el supuesto de sus diversas modalidades. Como lo es.también de su continuidad en el tiempo. La conciencia no es 
nada permanente y estable. Si de algún modo podemos definirla, en este sentido, es como una serie ininterrumpida de procesos, un fluir constante de vivencias que aparecen y desaparecen, que se renuevan de continuo como el agua de un río, de tal manera que cada momento; aunque contiene todos los momentos precedentes, es algo cualitativamente distinto de lo anterior, algo nuevo que no se ha dado nunca. La conciencia se transforma y enriquece en un proceso sin término. Pero, así como el agua de un río es justamente agua de un río, así también el constante fluir y transformarse de la conciencia, el complejo y permanente entrecruzamiento de sus vivencias constitutivas es un aconterer temporal de una única conciencia que mantiene su unidad y su continuidad en sus variaciones cualitativas.

La conciencia actual, en la que se verifica cada experiencia concreta, queda así como inscrita en una conciencia más amplia, no meramente vir. tual sino siempre viva y presente, que encierra la suma de todas las experiencias anteriores, de todos los conocimientos, nociones, sentimientos y valoraciones que se ha ido incorporando en el curso de su formación. Por eso se puede decir que la conciencia tiene historia. Pero, además, la conciencia actual incluye un cierto margen de anticipaciones, un futuro: un esperar, prever, prejuzgar, presentir, que le pertenecen con la misma propiedad con que hay en ella un pasado y un presente inmediatamente vividos. Pasado, presente y porvenir son las tres dimensiones de la conciencia en acto, unidas, más que por un enlace causal de hechos, por una unidad de sentido y valor que se manifiesta claramente por sus efectos, esto es, por la forma como cada una de esas dimensiones es capaz de determinar en su contenido las otras dimensiones. Esta unidad de sentido y valor se nos hace particularmente visible en la conciencia moral en la que cada momento se trasciende a sí mismo hacia el futuro y el pasado: en la conscientia antecedens que conoce, juzga, valora, previene, da las razones que hablan en favor o en contra de una acción y mide sus consecuencias inmediatas o remotas, y en la conscientia consequens que revierte sobre lo ya acontecido - pero que se mantiene como parte esencial del presente vivido- y actúa como juez que aprueba o rechaza, es decir, que confirma la validez de la acción cumplida o la hace entrar en un orden nuevo por un acto positivo de arrepentimiento. Pues es muy cierto, como lo ha observado justamente Scheler, que si bien en cuanto hecho real todo lo pasado es irreversible y no puede dejar de ser, cada experiencia de nuestra vida se mantiene indeterminada en su sentido e incompleta en cuanto al valor en tanto no ha producido todos sus efectos posibles, y esto no ocurre hasta el momento mismo de la muerte. ${ }^{2}$

Ahora bien: de esta conciencia plena y una; que tiene su propia historia y sus diversos modos de manifestarse, lo que me interesa destacar es su dimensión específicamente moral. Éste es nuestro verdadero punto de partida.

1 M. Scheler, "Reue und Wiedergeburt", en Von Ewigen in Menschen. 
¿Qué es la conciencia moral? Se la ha definido de muchos modos y desde puntos de vista muy distintos: conocimiento del bien y del mal; afirmación de la ley moral en el corazón del hombre, voz de Dios; imperativo social; exigencia sublimada de los instintos naturales; super-ego. Todas estas interpretaciones, y muchas otras que no viene al caso tomar en cuenta ahora, suponen sin embargo una definida posición teológica, metafísica, naturalista, sociologista, etc., que trascienden los límites de la pura descripción del hecho. No quiero decir que sean fálsas, pero lo evidente es que no pueden servirnos como punto de partida puesto que, en el fondo, en cada una de ellas está ya resuelto en lo esencial el problema. Pueden ser el resultado de una investigación, pero no su presupuesto. Conviene por tanto prescińdir de estas interpretaciones posicionales y adoptar, en forma provisional, una definición menos comprometida y, en cuanto sea posible, despojada de todo prejuicio doctrinario.

Claro está que semejante asepsia intelectual es sobremanera difícil o acaso de hecho imposible en una faena en la que cada afirmación compromete por entero a quien la hace y revela, aun sin quererlo, la propia personalidad del individuo, su biografía espiritual. No rehuyo desde luego el compromiso ni, por supuesto, ignoro hasta qué punto el hombre al plantearse un problema filosófico suele arrastrar consigo sus anteriores convicciones, sus ideas, sus creencias, sus presentimientos y prejuicios. Lo tengo bien en cuenta. Pero de lo que se trata ahora es de esforżarnos por aprehender la conciencia moral en lo que ella" es y no puede dejar de ser, en el.mínimo de sus determinaciones necesarias para que se nos descubra en su esencia, sin correr el riesgo de introducir inadvertidamente elementos extraños que la desf́iguren o la oculten.

En un sentido amplio y con una intención puramente descriptiva podría llamar conciencia moral aquella manifestación o módalidad de la conciencia plena que se refiere a la conducta humana dentro de la polaridad buenomalo. Bueno y malo son los dos términos extremos, aunque no los únicos, dentro de los cuales se actualiza y cobra su verdadero sentido la conciencia moral. Cón frecuencia hablamos de acciones nobles e innobles, altruistas y egoístas, justas e injustas, y de virtudes que con ellas se relacionan. Éstos son sin duda juicios éticos que se réfieren à particulares cualidades o condiciones morales, pero en última instancia todas tienen cabida dentro de esa contraposición extrema de lo bueno y lo malo, del mismo modo que en el quehacer artístico se contraponen to bello y lo feo y en el conocimiento científico lo verdadero y lo falso.

Indagar qué es propiamente lo bueno y lo malo que califica la conducta humana de manera específica desde el punto de vista moral no nos interesa por el momento, aunque bien sé que se trata del problema fundamental de la ética. Como tampoco nos interesa dejar establecido si la moralidad corres- 
ponde sólo a la conducta del hombre o puede hacerse extensiva igualmente al comportamiento de otros seres vivientes. Sin embargo, en lo que concierne a este punto, creo conveniente poner en claro desde ahora que esa última hipótesis que muchos investigadores sostienen apoyándose en ciertas semejanzas externas en el modo de actuar de algunos animales con la conducta humana, o bien en especulaciones teóricas como la syneidesis ${ }^{2}$ de Monakow - principio regulador de las funciones vitales o conciencia biológica que progresivamente se transforma en conciencia religiosa y moral-, me parece falsa porque al comportamiento propio de los animales le falta la condición esencial de toda acción verdaderamente moral, esto es, la libertad, que no es sólo poder hacer sino fundamentalmente posibilidad de ser. De todos modos, aunque la observación o la teoría pudieran llevarnos a la convicción de la existencia de un sentimiento o una inclinación "moral" en otros seres vivientes fuera del hombre, no se piense que por ello me he dejado dominar por un prejuicio al definir la conciencia moral como aquella que se refiere a la conducta humana en su relación con lo bueno y lo malo, porque mi punto de partida es la experiencia concreta y la verdad es que no conocemos otra experiencia que la nuestra propia. Si de alguna manera podriamos entonces hablar'de acciones morales en otros seres sería sólo como resultado de una proyección antropomórfica que nos coloca en el terreno de la hipótesis, de lo que tal vez sea o no sea, que a toda costa quiero evitar.

Ahora bien: esta descarnada caracterización de la conciencia moral, que apenas dice lo estrictameñte necesario, debe ser completada con otras determinaciones que la enriquecen y la perfeccionan sin sacarla de los límites provisionales que nos hemos impuesto por razones metódicas. En el fondo se trata de una explicación de lo que ya está contenido en ella.

La conciencia es primordialmente activạ. Esto no quiero decir que en sí misma sea acción pura. La conciencia en cualquiera de sus formas es siem-

2 La palabra griega syneidesis, de donde se deriva la latina conscientia, significa al pie de la letra un con-saber que según las épocas tha sido intrepretado como un con-saber con Dios o consigo mismo. Originariamente, en su dimensión moral, el concepto de syneidesis alude al sentimiento de culpabilidad y a los remordimientos que atormentan el alma culpable porque en ella se hace presente la mirada divina a la que nada queda oculto por mucho que nos esforcemos. Sólo más adelante, particularmente en los estoicos, se aplica al propio enjuiciamiento del hombre que se vuclve sobre sí e incluye lo que suele llamarse "buena conciencia". En la Edad Media, la escolástica entiende la syneidesis (synderesis) como una disposición natural, la lex naturalis o principios generales de la razón que Dios ha puesto en la naturaleza humana y de acuerdo a la cual el hombre debe regular su vida. Aunque desprendida de la tutela divina, esta idea de una ley natural, de una conciencia natural de lo bueno y lo malo aparece, con diversos matices, en todas las formas del apriorismo ético moderno. Como queda dicho, Konstantin Monakow la interpreta en el sentido naturalista biológico de un principio regulador de las funciones vitales, cuya fuerza biológicamente expansiva llama forne, y que se convierte progresivamente en conciencia moral y religiosa. 
pre un saber, tanto si se lo piensa en el scritido amplísimo de un simple tener noticia de algo como si, con mayor rigor, se lo entiende en el sentido de un sáber que se sabe, vuelto sobre sí, crítico, objetivo. " La conciencia moral es un con-saber ề implica estimaciones $\mathrm{y}_{\xi}$ juicios con caracteres propios $\mathrm{y}$ bien definidos: es intuición, juicio, sentimiento y acción a un mismo tiempo, indisolublèmente unidos. Por lo demás, toda conciencia es en cierto modo activa, que no otra cosa-significa su intencionalidad, su necesario referirse a algo como su objeto, aunque esto no debe interpretarse en el sentido común de acción. Pero la conciencia moral es activa en un sentido particular y más preciso que conviene subrayar. Lo que pasa es que la forma de vivencia que caracteriza a la conciencia moral es la de un tener que hacer esto o lo otro, tomar posición, decidirse en una situación dada. Aunque necesariamente incluye un elemento teórico, un conocimiento, un saber, no ès éste el que la define. I a vivencia moral tiene sin duda un carácter muy distinto del que tiene la vivencia teórica como tal, en sí misma. Así, lo que yo experimento cuando se me dice que dós y dos suman cuatro, que el agua hierve a cien grados o que una cosa no puede ser y no ser al mismo tiempo es muy distinto de lo que en mí acontece cuando se me dice, o me digo a mí mismo, que no debo matar o que debo respetar los derechos y los bienes ajenos. La diferencia es notoria: en el primer caso se trata de una proposición que enuncia lo que algo es, el modo de ser de una cosa, sú existencia y consistencia; en el segundo caso, lo que yo vivo en mi conciencia es la necesidad de obrar de úna manera dèterminada. La vivencia moral toma para mí la forma de un sentirme obligado, de un imperativo que me coloca en la situación de tener que decidirme en sentido afirmativo o negativo. Esta aprobación o rechazo, que implica también la obediencia o no obediencia a lo que se.me exige, es la actitud propia de la conciencia moral, manifiesta incluso en aquellos casos en los que. erróneamente pretendemos mantenernoṣ ajènos a toda decisión:

Prohibiciones y mandatos que reclaman una actitud de aprobación o rechazo, de obediencia, o no obediencia, es decir, siempre, la necesidad de elegir un camino, de decidir entre dos o más formas posibles de obrar, constituyen la peculiar estructura de la conciencia moral, fundamentalmente distinta, por lo consiguiente, de la conciencia teórica que se manifiesta en el asentimiento o no ásentimiento, esto és, en tener por verdadero o falso el enunciado de una proposición. Én la vivencia teórica entiendo el significado de la proposición, - lo que ella enuncia, y me limito a reconocerla como verdadera o falsa. Esto es lo que hace el teórico, el investigador, el hombre de ciencia en tanto se mantiene en el plano puramente científico. La conciencia teórica es pór eso en lo esencial pasiva. Este no significa por supuesto desconocer lo que hay de activo en el modo intencional que se refiere al ser de las cosas, en el afán de saber, en la búsqueda de la verdad y 
en todos los procesos que a ella conducen. Pero es pasiva en cuanto la vivencia de lo verdadero y lo falso no trae aparejada sin más la exigencia de obrar en un sentido o en otro. $Y$ cuando esto acontece es porque ya se ha trascendido del plano teorético al propiamente moral.

No creo que exista dificultad alguna para comprender lo que con esto quiero decir. Es bien claro que, en principio al menos, en el hacer científico y en el saber común yo puedo mantenerme en el dominio rigurosamente teorético, de tal manera que mi particular vivencia del tener por verdadera o falsa una proposición en modo alguno afecta mi conducta ni compromete mi ser moral. Pero también -y esto no es algo puramente circunstancial sino una exigencia del hombre en la plenitud de su ser-, yo puedo tomar una actitud más o menos definida respecto a lo que me es dado como verdadero o falso o a lo que deductivamente infiero como tal. Por lo pronto, puedo muy bien desinteresarme por completo de la verdad o falsedad de las cosas y acomodar mi vida a lo que me dice la experiencia natural, a lo que según ella me resulta conveniente o inconveniente. No menos importante o, tal vez, más como actitud concreta es empeñarme en tener por verdadero lo que sé falso o por falso lo que sé verdadero, es decir, cerrarme a la verdad por cualquier motivo que fuere. Aquí, sin duda, hay algo que trasciende ya la pura teoría, algo que va más allá del hacer científico en sentido estricto. Se trata, como se advierte, de una manera de comportarme respecto al problema de la verdad y a mi propio saber de las cosas; se está ya en la esfera de la conducta humana en relación con lo bueno y lo malo, con lo que debe ser o no debe ser y, por consiguiente, en la esfera de la conciencia moral.

Esta notoria diferencia entre mi reconocimiento de lo que es verdadero o falso y mis actitudes posibles frente a ese reconocimiento, actitudes que trascienden el plano de la pura teoría, nos permite ver claro no sólo que la conciencia moral es distinta de la teórica, sino también que ella se actualiza en las restantes formas de la conciencia plena y, en cierto modo, se les superpone. La conciencia moral actúa en las demás expresiones de la conciencia, las juzga y las regula en función del todo de la vida del individuo. Esto no significa, claro está, que la conciencia moral deba interferir en todas las manifestaciones del espíritu humano, regular su desenvolvimiento y aplicarles sus criterios y valoraciones. La ciencia, la literatura, el arte, la política, la economía tienen sus propias formas y leyes independientes de la moralidad que ésta no puede forzar ni desconocer. Es obvio que no se puede juzgar con criterio ético lo estético en sí, lo científico, to económico. Pero, desde el punto de vista supremo de la realidad integral del individuo, de su ser personal, todo cuanto hace puede y debe ser sometido a un juicio de orden moral que, dejando intactas las formas propias de cada una de esas expresiones del quehacer humano, las califique de buenas o malas, es decir, de 
acuerdo a los criterios específicos del-enjuiciamiento ético Así, parà lás llamadas artes visuales, como para la música o la literatura, son igualmeñte válidas sus-múltiples formas, modalidades y estilos, aủ los más contrapuestos, y nadie podrá juzgar moralmente a otro porque no coincida con sus gústos personales o con su particular concepto de lo que es el arte; por ejemplo. Empero, sí cae en el juicio moral, porque en éste está en juego el sentido total de la vida del individuo, la autenticidad $o$ inautenticidad de la expresión artística. La palabra deshonesto con que solemos calificar al artista, escritor o poeta que no siente ni esta convencido de lo que hace; pero que adopta la postura que juzga más conveniente para satisfacer intereses de otra indole, es un jûicio ético que se impone necesariamente, no por la calidad intrínseca de su arte, que no se trata de eso, sino por la intención puesta en él, por sus propósitos. $\mathrm{El}$ juicio apunta aquí a la totalidad del individuo; no a lo que hace, sino a lo que él es?

- Lo evidente, y esto é lo que ahora me interesa ante todo destacar, es que en la conciencia moral hay siempre algo más que en la conciencia teórica. Este más es esa particular vivencia del sentirse obligado, si bien, como se verá de inmediato, no basta pará definirla. Entre proposiciones puramente enunciativas como: esta pared es blanca o los tres ángulos de un triángulo suman dos rectos - Sean o no verdaderas-, y proposiciones que contienen un mandato o una prohibición la diferencia es notoria Las primeras corresponden a la conciencia teórica; las segundaş, en cambio, a la conciencia moral. Conviene, sin embargo, advertir que, esta diferencia la experimentamos también en proposiciones que se refieren a la conducta humana, a modós posibles del obrar, según contengan o nó un elemento imperativo junto al necesario elemento enunciativo: $\mathrm{Si}$, como ya lo he señalado en otro lugar, se me dice:- el röbo és un hecho antisocial, perjudiça a los intereses individuales y colectivos porque destrüye la armonía de la vida en común y priva a la víctima de la posesión y el goce de sus bienes, en una palabra, el robo es malo; o bien, todo ser humano es dueño de su vida y nadie puede despojarle de ella, en ambos casos yo entiendo el significado de esas proposiciones y las tengo por verdaderas o falsas, pues es muy claro que tanto puedo aceptar que el robo y el asesinato son malos como, a la inversa, sostener que la propiedad privadá no existe y que nadie es dueño de su vida." Pero, si sobre la base de esos enunciados teóricos o teórico-prácticos se configurá el mandato positivo por el cual se me ordena o mé ordeno a mí mismo no robar y no matar: "puesto que el robo" y el asesinato son malos, no deben ser y, por tánto, yo no debo robar ni matar" - aparece un nuevo elemento qửe no estaba en la proposición teórica y ante el cual no basta ya el asentimiento o no asentimiento. Lo nuevo que aparece el el momento compulsivo que en la conciencia mora l se manifiesta -en esa particular vivencia del

3. En el câp "Deber, Deber Ser y Valỡ" de mi libro, Vacación y Moralidad, 1949. 
séntirse obligado. Es indiferente, en tales casos, si el momento compulsivo proviene de un imperativo ajeno como sucede cuando se me dice: no debes robar, no debemos robar, ningún hombre debe robar, situación que plantea a mi conciencia el problema de la legitimidad del mandato; o bien, si nace de mi propia conciencia moral cuando, sin la intervención de un mandato ajeno, individual o colectivo, siento en mí mismo el deber de no robar porque, más allá dēl deber hacer que expresa la norma, tengo la intuición inmediata del deber ser que la fundamenta. Como es también indiferente, en otro sentido, de la forma enunciativa de la norma, pues la compulsión aparece lo mismo en la fórmula no debes robar como en no debes codiciar los bienes ajenos o debes respetar la propiedad de los otros.

Pero con decir que lo que caracteriza la conciencia moral es esa vivencia del sentirse obligado no está dicho todo ni lo que más importa. Pues ocurre que, en un sentido lato, el sentirse obligado es propio de toda conciencia práctica y no sólo de la moral. Subrayo expresamente- el carácter vivencial del sentirse obligado de la conciencia práctica en general, porque la simple idea de necesidad no basta. Hay una necesidad natural y una necesidad de orden lógico y matemático que nada tienen que ver con la conducta humana como tal. La piedra cae con necesidad y dos cosas iguales a una tercera son necesariamente iguales entre sí. Pero, aunque soy consciente de esas necesidades ni la una ni la otra son necesidades mías. Lo que es en sí necesario puedo reconocerlo y admitirlo, pero no es una necesidad para mí, es decir, no implica esa particular vivencia del sentirme obligado. La idea de necesidad es, en su extensión, mucho más amplia que la del sentirse obligado; y ésta es la que verdaderamente nos interesa. Se trata ahora de ver claro en qué consiste la vivencia específica de la conciencia moral en oposición a la conciencia práctica en general. La diferencia se revela en el distingo que es preciso establecer entre la vivencia del tener que hacer algo y la vivencia del deber hacer algo. Si bien a menudo se las confunde, la diferencia es esencial y conviene dejarla establecida. ${ }^{4}$

Fines y medios determinan la acción humana. El hombre es el ser que obra por fines: unos inmediatos, limitados y bien definidos; otros más generales y remotos. Para alcanzar esos fines, infinitamente variables en su contenido, debe procurarse los medios que les sean adecuados. La selección de los medios puede sin duda variar de una persona a otra y según las circunstancias, pero en todos los casos tienen que adaptarse al fin propuesto.

Aunque en rigor fines y medios no se bastan a sí mismos, porque tódo fin propuesto por el hombre presupone una valoración, podemos por el momento prescindir de este aspecto del problema dejando en pie, como esquema

4 La confusión se acentúa en nuestro idioma porque carecemos de la diferenciación más o menos precisa qúe, por ejemplo, en alemán tienen los verbos müssen y sollen que expresan respectivamente un tener que hacer algo para algo y el deber propiamente moral. 
básico, ese complejo sistema de fines y medios: medios para fines que a sü vez son medios para otros fines más generales, con los cuales el hombre tiene que hacer su vida. Si yo quiero un fin, debo querer también el medio, es decir, hacer del medio un fin más inmediato y provisorio. Querer el medio se deduce analíticamente de querer el' fin. Cualquiera sea el fin que me proponga no puedo dejar de querer el medio. Si no quiero el mediồ es porque en realidad, y aunque a veces no lo advierta, ya no quiiero el fin; éste ha desaparecido de mi intencionalidad volitiva. Querer el medio es, pues, una necesidad que mi conciencia vive subjetivamente como un imperativo, esto es, en la forma de un sentirme obligado. El imperativo rige la acción.

Pero este imperativo, como lo ha puesto bien en claro Kant, es hipotético, es decir, vale sólo con la condición de que yo quiera un fin determinado: sea un fin posible, como ser abogado, médico, industrial, escalar una montaña, construir una mesa o un barco, sea un fin real, esto es, un fin que de hecho, por su condición natural, quiere el hombre normalmente, como vivir o ser feliz. No estoy sin duda obligado a quérer este o el otro fin; inclüso puedo no querer vivir. Pero si quiero vivir o, más específicamente, si quiero hacerlo de una manera determinada: médico, abogado, comerciante, etc., estoy obligado a querer los medios que conducen a ese fin mientras éste se mantiene como fin concreto, inmediato o mediato, de mi acción.

A estos imperativos hipotéticos contrapone Kant el imperativo categórico, absolutamente incondicionado, sin relación a ningún fin posible o real. Desde luego, se pueden discutir o rechazar por completo todos o, algunos de los caracteres que Kant asigna a la ley moral, por ejemplo, su necesaria universalidad y su racionalismo extremo, pero lo indiscutible es que ha dejado establecida con todo rigor la manifiesta oposición entre el tener que hacer algo dadas ciertas condiciones y el deber propiamente moral. Kant habla indistintamente de deber, peró es evidente la diferencia de sentido que tiene el vocablo en ambos casos.

Existe sin duda una forma del deber y una conciencia del deber que no tiene su-origen y fundamento' en la prosecución de un fin determinado, que no es una "regla de la habilidad" ni un "consejo de la prudencia", sino que se nos impone sin condiciones, con absoluta independencia de nuestros intereses y deseos subjetivos. Existe un orden específicamente moral que establece normas imperativas para la.conducta, que prohibe ciertas acciones y exige otras sin preguntarnos si lo queremos o no lo queremos, si están o no entre nuestros fines posibles o reales.

De hecho, toda nuestra vida se halla regida por un sistema más o menos amplio y complejo de normas con relación al cual ciertas acciones se nos aparecen como debidas y otras como no debidas; sistema que es en sí independiente, aunque no por ello necesariamente opuesto, a lo que el orden jurídico, en su tiempo y lugar, establece por su parte como lo lícito 
y lo ilícito. Ni las reglas técnicas de la habilidad o de la prudencia ni las normas jurídicas pertenecen por sí a la conciencia moral. Unas y otras obligan, pero no son para la conciencia deberes absolutos. La vivencia del deber y no simplemente la del sentirse obligado constituye, pues, la verdadera conciencia moral.

Sin embargo, esta vivencia del deber es en principio, para la conciencia inmediata, sólo la de un deber hacer, es decir, la de un deber de obligación. Nuestro mundo moral, aquel dentro del cual nos movemos y actuamos en la vida diaria y cuya presión sentimos de continuo como una permanente limitación al libre juego de nuestras inclinaciones subjetivas, más que un sisterna de principios abstractos o de intuiciones de lo debido es un conjunto de prohibiciones y mandatos que si bien no tiene tras de sí un aparato represivo de sus violaciones nos obliga con mayor fuerza que las leyes jurídicas y que las normas comunes de los usos y costumbres.

Este deber hacer o deber de obligación se opone a nuestras tendencias o impulsos subjetivos. Espero que se me entienda bien porque estoy muy lejos de compartir cualquiera de las teorías éticas que conciben a la naturaleza humana en permanente oposición a lo que debe ser, al orden moral. Es falso, a mi juicio, afirmar que todas nuestras tendencias espontáneas son por sí mismas contrarias al deber y que, por lo consiguiente, la moral consiste en oponerse a ellas, en dominarlas. $\mathrm{Ni}$ aun Kant cuyo rigorismo, mal interpretado, ha sido fuente de tantas confusiones, cae en semejante error. Lo que Kant sostiene es que las inclinaciones, deseos y tendencias naturales del hombre no pueden servir de fundamento a una ley moral objetivamente válida. La ley moral es un factum de la razón pura y, en su estructura, estrictamente formal, carente de todo contenido. Sin duda Kant no está en lo cierto al afirmar que todas las inclinaciones son sensibles por lo que deben ser excluidas por completo del orden moral fundado en el deber, esto es, "en la necesidad de una acción por respeto a la ley", cómo si el amor al prójimo, la caridad, la benevolencia no tuvieran contenido moral alguno, ni hubiera en el hombre otros sentimientos que los derivados de los sentidos. Pero aun así la verdad es que no contrapone de una manera radical $e$ inconciliable la tendencia al deber, hasta el punto que la felicidad, en cuya idea se reúne según Kant la suma de todas las inclinaciones, debe ser asegurada por todos, siempre claro está que se lo haga no por inclinación sino por deber, en cuyo caso, y sólo entonces, la conducta tiene un verdadero valor moral..$^{5}$

Las inclinaciones tienden a fines que pueden ser contrarios al deber, pero no necesariamente. Esto es bien claro y no creo que sea menester abundar en argumentaciones contra esa errónea concepción que escinde de tal

5 Kant, Fundamentación de la Metafísica de las Costumbres, "Tránsito del conocimiento vulgar de la ráán al conocimiento filosófico". 
modo la reälidad humana que después resulta difícil o acaso imposible reintegrarla en su unidad. M. A. Bloch ha sübrayadó con particular acierto que quien se empeñe en mantener como irreductible la oposición aparente entré el deber y la tendencia, tendrá la doble tarea de mostrar cuál es la fuente de un deber que él áisla por hipótesis de todos los móviles concretos que suministran al hombre todas sus tendencias; y cómo puede suceder que ese deber proyecte sin embargo sobre el plano de la vida afectiva los p̀laceres y dolores; incluso específicos, ligados a su cumplimiento o a su violación:" Si bien el "naturalismo moral auténtico" de Bloch, que rechaza tanto al naturalismo común como a las doctrinas del deber abstracto necesariamente opuesto a las tendencias, no me parece aceptable porque no distingue las diferencias cualitativas esenciales entre las formas puramente sensibles y las formas superiores de las tendencias, creo conveniente destacar su justa reivindicación de las tendencias humanas en el planó de la moralidad, cosa que por otra parte, pero con un sentido completamente distinto, ha hecho,también $M$. Scheler, para quien las téndencias, aunque no son por sí fines de la voluntad, se hallan impregnadas de valor y no son por tanto éticamente indiferentes.

Si, no obstante, puedo decir, de acuerdo con Scheler y N: Hartmann, ${ }^{7}$ que el deber hacer se opone a nuestras tendencias e impulsos, es porque entiendo que, cualquiera sea la relación existente entre tendencia, deber y valor, la norma que prohibe o manda, es decir, to que solemos llamar deber hacer o deber de obligación sólo adquiere sentido y se justifica para la conciencia moral de una persona si hay en ella una tendencia, una inclinación o un deseo contrario a lo que debe ser. ¿Qué sentido tendría que se me ordene o yo mismo merordene no mentir si no hay en mínclinación alguna para hacerlo y mi conciencia intuye la veracidad como lo que es en sídebido? Si para mi conciencia la veracidad, la justicia, el respeto a la vida y a los bienes ajenos deben ser sin condiciones, y si yo tiendo a obrar de acuerdo a esa exigencia ideal, me parece realmente absurdo que se me ordene lo que debo hacer por medio de una prohibición o un mandato. En cambio, si dé un modo u otro tiendo a la no realización de lo que debe ser, tiene cabal sentido y se comprende cualquiera prescripción que me obligue.

Lo cierto es que la conciencia "vive" el debcr hacer como una compulsión, como algo que se le impone aun a su pesar, que le obliga. Ahora bien: es obvio que en esa vivenciầ del sentirse obligado nada hay que asegure que realmente de $\dot{b}$ e sér lo que la norma ordena. ¿Por qué no debo robar? ¿Por qué se me prohibe hacerlo si ése es mi deseo o conviene a mis intereses? Desde luego, queda por completo al margen de la cuestión lo que prescribe

6 M. A. Bloch, Les-Tendences et la Vie Morale, Paris igis:

7 Max Scheler, Der Formalismus in der Ethik und die materiale Wertethik, Nicolai - Hartmann, Ethik. 
el orden juridico vigente que tiene su razón de ser y su estructura propias, aunque en última instancia se inspire en principios éticos. Una cosa es el orden de la legalidad y otra el de la moralidad; y lo que ahora nos interesa es éste, es decir, la vivencia específica de lo moral.

Por lo pronto es bien claro que la intensidad vivencial de la conciencia del deber no tiene relación alguna con el deber ser. Ladrones y asesinos de profesión suelen tener un sentimiento muy agudo del deber profesional, sobre todo aquellos que forman parte de grupos bien organizados, y no por ello el robar y el asesinar deben ser. A veces el sentimiento del deber, vinculado con ciertas convicciones y creencias religiosas, alcanza formas y límites insospechados. Es un hecho bien conocido que en algunas tribus primitivas la obligación de vengar la muerte de un familiar, que se supone causada por las artes mágicas de un miembro de otra tribu, es vivida por el individuo con tal intensidad que incluso puede provocarle la muerte si no logra dar cumplimiento, con el asesinato de algún miembro de la tribu enemiga, a lo que intimamente siente como un deber irrenunciablé. Es muy posible, pues, sentir como debido lo que no debe ser, al par que puede no ejercer sobre nosotros compulsión alguna lo que realmente debe ser. Esto es lo que ocurre, según queda dicho, en aquellos casos en los cuales nuestro querer sigue espontáneamente la dirección de lo que es dado como debido, por. lo que se hace innecesario un mandato o una prohibición. En definitiva, lo que importa tener en cuenta es que el sentirse obligado, cualquiera sea la intensidad de eśa vivencia, no asegura la bondad de lo que se nọ exige, del mismo modo que el hecho de sentirse compelido a tener por verdadera una proposición no asegura su verdad.

¿Por qué entonces debo o no debo hacer esto o lo otro? ¿Por qué debo ser veraz, fiel; honrado, justö? ¿Por qué no debo matar ni robar ni mentir? ¿Qué o quién me garantiza la legitimidad dè lo mandado o prohibido? ¿No será esto una disposición arbitraria, algo que se me ordena sin ningún fundamento o por razones que no alcanzo a comprender? o bien, ¿no me estaré engañando a mí mismo cuando me digo: no debes hacer esto, ya sea de acuerdo a las normas morales corrientes, ya sea, fuera de ellas, porque así lo entiendo, porque hay en mi una inclinación, una tendencia o un deseo ocasional contrario a lo que me parece que debe ser? Ése es el punto en que a partir de la vivencia del deber hacer, del sentirme obligado, la conciencia adquiere su sentido verdaderamente moral. La conciencia moral se actualiza en el seno de la conciencia plena y surge como tal cuando el hombre en cada situación concreta busca los fundamentos de su conducta y justifica por ellos todas las manifestaciones de su vida.

A mi juicio, el único fundamento posible de todo mandato o prohibición moral reside en el deber ser de lo que la normà exige. El mandato y la consecuente situación vivencial del sentirse obligado se fundan en el deber 
ser. En resumidas cuentas, esto significa que si yo, por ejemplo, debo ser veraz, tenga o no la intención de serlo, es porque la veracidad debe ser. No interesa ahora saber si la veracidad debe ser universalmente. Es un hecho real que las morales cambian según tiempo y lugar. Lo que importa es que debà ser para mi conciencia. Si la norma existe y me obliga de alguna manera, la obediencia a esa norma se justifica y tiene valor moral sólo si para mi conciencia lo que ella manda o prohibe.debe ser realmente. Lo que vale para mi Conciencia como factor determinante de mi conducta tiene, pues, su fundamento en la vivencia del deber ser contenido en la norma. Así, para retomar un ejemplo que ya he utilizado en otra ocasión, si la justicia no me fuere dada como algo que debe ser no valdría para mí que yo deba" ser justo $y$, por lo consiguiente, cualquier mandato que me obligue a serlo, aunque estuviere inspirado en las mejores razones, no sería para mi conciencia más que una compulsión arbitraria, una orden que experimento como un deber, pero que carece por completo de sentido y valor moral, cualquiera sea la autoridad de quien me ordena y cualquiera sea la intensidad de mi sentimiento del deber. Si, por lo tanto, yo debo ser justo, es porque para mi conciencia la justicia debe ser. ${ }^{8}$,

Esto no excluye por supuesto que lo que debe ser llegue a mi conciencia a través del mandato ajeno o del ejemplo. Sin duda, como sucede de hecho en la formación de toda conciencia moral, yo descubro ló que debe ser a través de lo que debo hacer, es decir, a través del sistema de normas que rige mi conducta en el grupo social. Este sistema de normas es una realidad social con la que me encuentro y a la que por lo común ajusto mi conducta porque representa el sentir moral del grupo al que yo mismo pertenezco. Lo que exige de mí no es por sí una imposición arbitraria puesto que cuando la sociedad reclama de quienes la integran una cierta forma de comportarse, lo hace siempre desde esa moral propia que la define, desde lo que. para ella debe ser. Pero es bien claro que lo que califica mi conducta en sentido moral no es la simple obediencia a las normas sino mi propia conciencia de que realmente debe ser lo que ellas ordenan. De lo contrario, ¿cómo podría yo saber si lo que se me ordena y que yo vivo como un deber es lo bueno y lo que yo debo querer? El valor moral de la obediencia sólo puede medirse por el valor moral de lo mandado; y ese valor tiene que serme dado de algún modo para que la obediencia a la norma que lo contiene sea tam- . bién un valor para mí, algo que para mí debe ser.

En lo que concierne al valor de los modelos como guías espirituales y morales, es muy probable que su influencia sea en la práctica mucho mayor de lo que suele suponerse. Pero es obvio que lo que puede hacer el otro, o los otros, con su ejemplo, enseñanzas y consejos, es sólo señalarnos. el camino para nuestra propia conciencia de lo que dẹbe ser, y en modo alguno.

8 R. Virasoro, op. cit. 
sustituirla. Por muy alto que sea mi reconocimiento de la bondad moral de otra persona, mi conciencia no puede hacer otra cosa que seguirla, abrirse a ella para descubrir por sí lo que debe ser o no debe ser. El deber hacer que emana del modelo no es propiamente un legítimo deber ser para mí si no lo intuyo como tal a través de él. En otras palabras: si en una determinada situación concreta $o$, en términos más generales, si para hacer mi vida, tomo a otro como ejemplo y quiero imitarlo en lo que él hace y en $10^{\star}$ que él es, no es simplemente porque él lo hace -que esto implicaría un total renunciamiento a mi autonomía moral- sino porque en su hacer y en su modo de ser descubro lo que para mí debe ser. El querer seguir su ejemplo no es moralmente valioso en sí mismo, sino que lo es por referencia al contenido de valor que su ejemplo encierra. Por eso el modelo no se impone sino que se elije; y se lo abandona tan pronto se advierte que su ejemplo no ejerce ya atracción alguna; es decir, cuando ya no me llama hacia él, cuando el camino que él me señala no es mi camino, el que yo estoy llamado a seguir.

Cualquiera sea, pues, el origen de las normas que rigen mi conducta y que mi conciencia moral "vive" como un deber hacer, como una obligación, lo que realmente importa es saber si esa obligación se justifica, si tiene sus fundamentos, si lo que ella manda debe ser. A la clásica pregunta central de toda moral práctica: ¿qué debo hacer?, sólo puede respondersè: lo que debe ser. Si yo debo ser justo, veraz, honrado, respetuoso de la vida y de los bienes ajenos, es sólo porque para mi conciencia la justicia, la veracidad, la honradez, el respeto por la vida y los bienes ajenos deben ser.

Ahora bien: ¿de dónde saco yo que la justicia debe ser, o la veracidad, la honradez, la templanza, la benevolencia, en fin todas las llamadas virtudes éticas? En términos más generales: ¿đe dónde saca la conciencia las razones o los motivos de la acción moral? Bien entendida, sólo puede ser de sí misma, de su propia experiencia. La conciencia moral es en cada persona el fruto de una experiencia continua que la crea, la forma y la transforma en el ámbito y al amparo de la experiencia colectiva dentro de la cual se halla inmersa. ${ }^{9}$

La conciencia moral es una estructura compleja hecha de sentimientos, juicios, valoraciones; una suma o, con más exactitud, un todo unitario de experiencias acumuladas en el curso de la vida $y$, en parte también, surgidas espontáneamente en cada una de las situaciones que plantea el existir cotidiano. Ya antes me he referido a la continuidad y a la unidad de sentido y valor de toda conciencia, en su historia y en sus múltiples expresiones;

9 Se comprende por lo dicho al comienzo de este trabajo que tomo el concepto de experiencia en el sentido amplio que corresponde y, desde luego, muy distinto de la acepción común de mera experiencia sensible. 
al necesario trascender de la conciencia en acto hacia el pasado y hacia el porvenir. Pero no menos importante es tener en cuenta que la conciencia de cada persona no se forma por sí sola, aislada por completo de los demás. Toda experiencia individual se inscribe en una experiencia más amplia y general, la de los otros, la de todos. De"ella se nutre y en ella se sostiene. La formación de la conciencia moral presupone la experiencia común, las ideas, los principios normativos, los sentimientos y los juicios morales del pequeño grupo social en el que de hecho vivimos, de la familia, pueblo, nación, círculo de cultura, en una palabra, presupone lo que solemos llamar moral colectiva; incluso también las ideas y las experiencias morales de otras épocas o de'otras culturas que llegan a nosótros y se incorporan a nuestra conciencia a través de la historia, de la literatura, del arte, de la reflexión filosófica.

La conciencia moral se forma en la moral colectiva. Más aún: impregna ésta de tal manera la conciencia individual que por lo común una-y otra coinciden. Es bien sabido que la vida espiritual de una persona y su ethos en particular reflejan siempre, con raras excepciones, la vida espiritual y el ethos colectivo. Al menos en las primeras etapas en el desarrollo de un îndividuo, en lo que podríamos llamar conciencia naciente, lo bueno y lo malo, lo que para él debe ser o no debe ser no es otra cosa que lo que la sociedad exige, lo que ella permite o prohibe. Las condiciones efectivas de la formación de la conciencia moral están dadas siempre y necesariamente por el todo social, aunque a veces, en el curso de la historia, algunas individualidades geniales trascienden sus límites y abren nuevas perspectivas al mundo moral de su tiempo.

Pero esta conciencia del deber que el hombre se forma en el seno del ethos común sólo alcanza verdadera categoria moral cuando logra desprenderse de la sujeción a lo colectivo, cuando se constituye como conciencia propia, personal, capaz de determinarse a sí misma de acuerdo a su particular experiencia. Obedecer a las normas u oponerse a ellas sin razón alguna es, en rigor, indiferente para el ser moral de la persona. Carece igualmente de significación buscar el fundamento de cada acción concreta en la moral común, aceptando pasivamente lo que según ella debe ser. Aun en aquellos casos, Ios más frecuentes por cierto, en que la experiencia del individuo y lo que para él debe ser coinciden por completo con el deber ser colectivo, es esa experiencia personal la que condiciona él valor moral de la conducta. Lo social es el subsuelo y el punto de apoyo con el que necesariamente hemos de contar para nuestra propia experiencia, pero es ésta la que realmente importa, si es que la norma que rige nuestra conducta más que una constricción, más que una fuerza que nos obliga, es una verdadera exigencia moral que libremente aceptamos porque para nuestra conciencia debe ser. Firmemente asentados en la realidad social que nos rodea y sin la cual. 
no podriamos ser hombres en la plenitud de su sentido, sin embargo la entrega incondicionadâ a lo social nos enajena y destruye en nosotros toda posibilidad de ser el si mismo que por propia vocación cada uno debe ser. Mi conciencia moral no tiene por qué oponerse necesariamente a la moral colectiva; pero no se confunde con ésta, no es esta misma, como de hecho sucede en quien vive aprisionado en el todo, sino que es $\mathrm{mi}$ conciencia, aquella con la cual yo tengo que trazar mi propio destino y de la cual no puedo prescindir sin negarme a mí mismo. Absolutamente autónoma, la conciencia moral sólo puede admitir como fundamento de la conducta lo que para ella debe ser, lo que como tal surge de su particular experiencia, de sus estimaciones y juicios. Ésta es la razón, no siempre tenida en cuenta, por la cual el deber no sólo nos obliga sino también nos atrae y es deseable para nuestra conciencia. Lo que simplemente se nos impone ejerce sobre nosotros una violencia que nos perturba y que en todo momento estamos dispuestos a eludir: En cambio, lo que sentimos como un deber, aunque llegue a nosotros a través de un mandato ajeno, mueve nuestro ánimo, nos atrae, y su cumplimiento provoca una alegría profunda, incomparablemente superior al placer que pueda proporcionarnos la satisfacción de cualquier deseo.

En unos apenas incipiente y como adormecida; en otros, viva, despierta, en permanente vigilia, con un rico contenido de experiencia que de continuo se ensancha y se perfecciona en el diálogo y a través del ejemplo, de la educación, de las sugestiones ajenas, es a su propia conciencia moral a la que el hombre acude en cada situación concreta, es decir, en todos los momentos de la vida, porque el hombre está siempre en situación, comprometido, obligadó a tomar decisiones y a resolver los conflictos que le plantean las circunstancias naturales de su existir y de su coexistir con los demás. Hay momentos en que los conflictos se tornan más agudos y la tensión de la conciencia es mayor, pero en ningún instante podemos prescindir de ella ni permanecer sordos a sus llamados, pues de hecho estamos embarcados en la acción, "prendidos en la trama de las circunstancias a las cuales debemos adaptar constantemente nuestra conducta". (G. Gusdorf.)

El conflicto está en la esencia misma de la conciencia moral. Su dialéctica propia es la de la contraposición entre lo que se puede hacer y lo que debe ser. Las doctrinas morales suelen oponer lo moralmente debido a los instintos naturales del hombre. Pero la verdad es que salvo condiciones anormales que escapan ya a la esfera moral en sentido estricto, el hombre no obra por instintos sino por fines determinados racionalmente. Sin duda, en la base de todo el hacer humano encontramos un complejo sistema de impulsos instintivos que condicionan la vida espiritual y moral. Sin instintos no hay vida, y sin vida no puede darse en el hombre ninguna forma 
de espiritualidad. Pero, precisamente, lo que mejor define al hombre en este sentido y lo coloca por encima de todo otro ser viviente es su capacidad para racionalizar sus instintos y convertir sus objetivos naturales en fines de la acción. Es por eso que el hombre puede ser mejor o peor que el animal, pero nunca igual (Scheler). El hombre no es un animal de rapiña, pero puede hacer del robo un fin; y sólo porque es un fin propuesto y querido por la voluntad tiene la significación moral que el instinto no puede tener en sí mismo. Los instintos no son buenos ni malos, carecen por completo de todo sentido moral y no se vé cómo se les puede contraponer en el seno de la conciencia a lo que debe ser. En realidad, cuando hablamos de buenos y malos instintos nos estamos refiriendo a las tendencias o inclinaciones, que no son instintos puros sino que representan un querer racional ciertos fines que se ha hecho tendencia o inclinación y, como tal, termina por identificarse en cierto modo con nuestro ser; es decir, representan un tender espontáneo hacia' algo que puede o no corresponder a lo que realmente debe ser, como sucede en aquellas personas de quienes decimos con $^{2}$ toda propiedad que tienen inclinación natural hacia la caridad, la modestia, la honradez, o bien hacia el robo, el crimen, la mentira.

Claro es que aúnque las tendencias poseen ya en sí un significado mo. ral, -no caen en rigor dentro del enjuiciamiento ético mientras no se actualicen en cada caso concreto y se conviertan en fines positivos de la acción por un acto de la voluntad. Con esto quiero decir que' si hày en mí una inclinación a la mentira no obro sin embargo contra lo que debe ser si no tengo la intención de mentir ni lo hago en cualquier situación que se me presente, si eso que es en mí una tendencia no se convierte en un fin racional de mi conducta. Las inclinaciones o tendencias propias de un individuo definen por lo común su personalidad moral. Pero sucede que la conciencia no es en ningún momento una realidad estática, congelada, que se ha cerrado a toda nueva evidencia. A menudo tropezamos con lo que repentinamente o al cabo de una larga experiencia se nos revela como lo en sí debido en oposición a lo que por tal teníamos hasta entonces. ¿Qué importa más: seguir nuestra inclinación moral y aferrarnos a ella o desprendernos de sus ataduras ante la evidencia de un deber ser que la contraría? Cualquiera sea la solución que demos al problema - y no creo que exista duda alguna si queremos mantener la autenticidad de nuestro ser- es sólo la intención que ponemos en la conducta la que tiene verdadera significación moral. La tendencia no basta: Por otra parte, el proponerse un fin contrario a lo debido no siempre revela una inclinación hacia ello, una "mala tendencia". Tanto o más frecuente es que, en determinadas circunstancias, el quẹrer hacer" lo no debido se manifiesta en quienes habitualmente tienden hacia lo que debe ser.

.. En uno u otro caso, lo que importa tener en cuenta es que en la con- 
ciencia moral no intervienen para nada los instintos sino los fines de la acción, lo que el hombre puede hacer en cada situación. Pero, y aquí tocamos ya el meollo de nuestro tema, lo que el hombre puede hacer tropieza con lo que, independientemente de sus- deseos subjetivos, debe ser. Así se origina el conflicto moral que nuestra conciencia resuelve en la sintesis de la acción o, con más exactitud, en la intención definida de obrar sea de acuerdo a su voluntad subjetiva, sea de acuerdo a lo que objetivamente debe ser. $L a$ vivencia del conflicto es la sustancia misma de la conciencia moral, lo que la constituye y la sostiene.

Se me ocurre que un ejemplo común, una situación posible entre otras muchas podría hacernos ver con mayor claridad la naturaleza del conflicto moral. 'Supongamos un funcionario público a quien se le presentá la oportunidad de obtener una apreciable cantidad de dinero a cambio de un informe o una resolución que favorece a determinada persona y perjudica a otras, violando con ello los deberes inherentes a su cargo. Supongamos también que se trata de un hombre honesto que se siente perturbado, quizá por vez primera, ante esta imprevista coyuntura, ocasión magnífica que acaso podría resolver para siempre sus dificultades económicas. Poco cuesta imaginar su diálogo interior, el juego de las incitaciones y resistencias que forman la trama de su conciencia moral repentinamente surgida al primer plano y urgida a tomar una decisión. Por supuesto, no tiene duda alguna que desde el punto de vista legal no le está permitido violar sus deberes y defraudar la confianza que se ha depositado en él. Pero lo cierto es que no faltan modos de eludir la responsabilidad y la sanción jurídica, y el delito podría muy bien quedar impune; todo consiste en hacerlo de tal manera que se mantenga totalmente oculto o con apariencias de legalidad. Sin embargo, hay algo' más, algo que le afecta no ya sólo como funcionario o como ciudadano sino como hombre. Ante la sociedad, familia y amigos ha gozado siempre merecida fama de hombre honesto, y aunque escape a la sanción legal no podrá escapar al desprestigio social. Pero, ¿es preciso que alguien se entere? Con evitarlo desaparece el problema. Más aún: si, a pesar de las precauciones tomadas, alguien se entera, ¿qué importaría eso en realidad? Tendría resueltas sus dificultades y es muy probable que con el tiempo su situación económica no sólo le asegure una vida tranquila sino que también le permita recobrar, como tantas veces sucede, el prestigio social perdido. Están, pues, dadas todas las circunstancias favorables, todas las garantías para hacer lo que conviene a sus intereses, y tanto puede orientar su conducta en un sentido como en el otro. Si el cumplimiento del deber le atrae, no menos fuerte es la tentación de satisfacer sus deseos y ambiciones. La conciencia moral "vive" el conflicto que necesariamente ha de resolver en la acción concreta.

Supongamos también ahora que, a pesar de todo, este hombre resiste 
realidad de'la vida humana es una, pero conviene mantenerla para facilitar la comprensión dentro del esquema prefijado.

El origen de estos conflictos entre los deberes reside en la condición sócial de nuestro ser. Es un hecho que, de una manera u otra, formamos parte de diversos grupos sociales: familia, profesión, medio cultural, pueblo, nación, que exigen de nosotrós modos de conducta a veces concordantes, pero a veces también radicalmente opuestos. Ésta es una experiencia común y cotidiana que nos obliga a tomar una décisión en cada caso concreto. ¿Qué debemos hacer ante dos o más formas contrarias del deber "que sin embargo tienen cada una de ellas su propia justificación y fundamento, su razón de ser, su contenido de valor?

Nuestra conciencia moral se enfrenta infinidad de veces con estas situaciones aún más difíciles de resolver que cuando el conflicto se plantea entre lo que el juicio moral discierne claramente como lo debido y lo no debido. En El existencialismo es un humanismo, Sartre nos pone el ejemplo de un jovien que no sabe qué conducta debe adoptar frente a las dos posibilidades que se le ofrecen: permanecer junto a su madre y ayudarla a vivir, o bien participar activamente en la defensa de su país en las fuerzas de resistencia de la Francia libre organizadas en Inglaterra. ¿Qué importa más en este caso: el deber filial o el deber patriótico? Estoy de acuerdo con Sartre en que no se le puede dar al joven un criterio definido para la acción, puesto que no se trata de optar entre el bien y el mal, sino entre dos formas distintas del deber. En lo que no estoy de acuerdo es en las razones que da para ello. Sartre pretende que como no existe ninguna moral inscrita que pueda señalarnos cuál es la actitud que corresponde, no nos queda otro camino que confiar en nuestros instintos. De las dos actitudes posibles la que se elige es la que vale. Lo que de veras importa, dice Sartre, es la incondicionalidad de la entrega, la libre decisión, prescindiendo de qué sea aquello que se elige. Pero es evidente que con esto se destruye la idea misma del deber, al par que se hace imposible el propio ejercicio de la libertad que precisamente Sartre quiere justificar a cualquier precio como condición esencial de la vida humana. Pues es muy claro que las dos formas del deber que se oponen en el ejemplo dejan de ser tales para convertirse en simples posibilidades de la acción, indiferentes en sí para la libertad. $Y$ ¿qué decisión podría ser verdaderamente libre si para el hombre, en este como en cualquier otro caso, todo es indiferente y tanto da lo uno como lo otro siempre que se mantenga la incondicionalidad de la entrega? Lo que no tiene valor alguno para la conciencia moral, lo que es en absoluto indiferente, obra en el mismo sentido que la más estricta determinación y toda posibilidad de elección queda en principio excluida. ${ }^{11}$ En definitiva, lo que Sartre sostiene

11 Sobre el problema moral en Sartre, exposición y crítica, puede verse mi pequeño libro Existencialismo y Moral: Heidegger y Sartre, 1957 . 
es una elección arbitraria, sin razón alguna, un puro confiar en el instinto: "elige lo que quieras, que eso que elijas es el bien, lo que vale". Pero una dècisión de esta naturaleza nada tiene que ver con la moral. El conflicto se esfuma, la vivencia del deber desaparece y, con ello, la posibilidad de una elección verdaderamente libre.

$\mathrm{Si}_{\text {queremos, }}$ pues, permanecer en el plano ético hemos de mantener la vigencia del conflicto, no entre dos maneras posibles de obrar sino entre dos formas del deber que reclaman pór igual una libre decisión de la voluntad, del mismo modo que lo que es dado a la conciencia como en sí debido exige su cumplimiento cuando el conflicto se produce entre lo que debe ser y lo que no debe ser.

¿Qué importa más entonces: el deber filial o el deber patriótico? Es bien claro que para dar una solución justificada y objetiva al conflicto que se le plantea a la conciencia moral tenemos que acudir a las razones en que una y otra forma del deber se apoyan, es decir, a sus fundamentos. Pero estas razones sólo podemos encontrarlas si las buscamos eǹ el marco más amplio de una justificación de todo deber ser.

¿Por qué hay algo que para la conciencia moral debe ser y algo que no debe ser? No se trata de preguntarnos por qué debo ser veraz y justo, o bien, por qué no debo robar ni matar. Ya sabemos que esos mandatos y prohibiciones tienen sentido para nosotros y nos obligan porque la veracidad y la justicia deben ser y el crimen y el robo no deben ser. Lo que ahora nos interesa es por qué la veracidad y la justicia deben ser y, en cambio, no deben ser el robo o el crimen, prescindiendo de que realmente exista en nosotros una tendencia o un deseo momentáneo de mentir, de ser injusto, de robar o matar.

Pues bien: en un sentido general, yo creo que el fundamento de todo deber ser reside en su contenido de valor. Así como todo deber hacer o deber de obligación se funda en el deber ser - pues de lo contrario no sería para mi conciencia más que una compulsión arbitraria sin contenido moral alguno--, así todo deber ser se funda a su vez en un valor. Que la veracidad y la justicia deban ser y no en cambio el robo y el crimen tiene por lo tanto su razón de ser, su fundamento: si la veracidad y la justicia deben ser, aunque todos los hombres fuesen justos y veraces o aunque no lo fuese ninguno, es porque la veracidad y la justicia son positivamente valiosas, es decir, algo que es dado a nuestra conciencia moral como un valor positivo, de la misma manera como nos es dado el valor negativo de la mentira, de la injusticia, del robo o del crimen. ${ }^{22}$

12 Esta posición que, como se advierte, es en lo esencial la de la ética material de los valores, aunque esto no significa que adhiera por completo a las conocidas pasiciones de M. Scheler y de N. Hartmann, queda sin duda un poco en el aire y puede parecer totalmente injustificada sin una cuidadosa fundamentación y un detenido análisis crítico de las diversas doctrinas morales que o bien consideran el deber como una categoría primaria 
El problema moral es en el fondo un problema de valoración. Esto no significa, desde luego, que demos valor a las cosas, en sí indiferentes, como pretende Sartre $y$, en general, todas las formas del subjetivismo ético, pues en tal caso, y esto es sobre manera importante a mi juicio, la conciencia moral no tendria la vivencia del deber que se funda en el valor como una exigencia que se desprende de su cualidad positiva. Todo deber ser es deber ser de algo y supone el ser de los valores; y, por tanto, supone también unả forma particular de experiencia en la que esos valores son dados a nuestra conciencia, si bien no se trata de la experiencia empírica que justificadamente tanto Kant como Scheler y Hartmann rechazan como fundamento de una verdadera acción moral. Dentro del objetivismo axiológico caben sin duda muchas posiciones, que no puedo ahora analizar ni discutir, desde el objetivismo absoluto hasta la tesis de Durkheim que fundamenta la objetividad de los valores en la realidad social. De todos módos, lo que me parece evidente es que el deber ser no es una categoría primaria y abstracta como Kant sostiene. Por el contrario; el deber es siempre un deber concreto y supone los valores y su forma particular de experiencia.

En el conflicto que plantea la oposición entre lo que debe ser y lo que no debe ser, entre el bien y el mal, es la conciencia del valor positivo de lo que debe ser y del valor negativo de lo que no debe ser la que sirve de fundamento a la acción y determina su valor moral. En la respuesta al valor se nos revela ahora la sustancia misma de la conciencia moral. Así como obedecer a los mandatos y prohibiciones, esto es, a las normas que obligan, carece de toda significación moral si no se tiene la plena conciencia de que lo que la norma ordena es realmente lo que debe 'ser, así también obrar de acuerdo al deber no tiene ninguna significación moral si no se posee al mismo tiempo la evidencia del valor positivo que ese deber ser contiene. Aunque el deber ser es, como se ha visto, el elemento esencialmente constitutivo de la conciencia moral, en última instancia lo que ella tiene presente es la cualidad de valor que el deber ser encierra. $Y$ justamente por eso, porque todo deber ser encierra un contenido de valor que lo fundamenta, es posible una libre decisión no sólo entre lo que debe ser y lo que no debe ser, según sea su valor positivo o negativo, sino también entre dos formas del deber, de acuerdo a la jerarquía de valor que cada uno de ellos contiene.

A mi entender sólo la ética material de los valores puede dar una solución con sentido y bien fundada al conflicto entre los deberes, conflicto que en la moral kantiana desaparece y en una moral como la de Sartre se re-

-en cuyo caso lo debido es lo que vale y no a la inversa como sostengo-, o bien fundan el deber moral en razones de orden teológico, racional, naturalista, específicamente biológico, etc. Creo conveniente advertir que este trabajo, muchos de cuyos puntos he tratado en forma muy somera, es sólo algo así como un esquema preliminar y básico de un tema que espero desarrollar con la amplitud que requiere y que ahora es imposible por razones obvias. 
suelve en un puro subjetivismo, en un elegir sin razón o por razones que nada tienen que ver con la moral. En estos conflictos entre los deberes es donde mejor se advierten los supuestos axiológicos del deber ser y, ádemás, la imposibilidad de guiarnos por las morales constituidas que en todos los casos expresan una manera de sentir los valores que no es necesariamente la de cada individuo. Si sólo se tratase de tener que optar por aquello que se nos señala desde una moral dada, sin que nuestra conciencia tuviere que participar en elló, tropezaríamòs con la sorprendente paradoja de no tener a quien acudir para que nos indique lo que debemos elegir sino precisamente a quien nada puede decirnos, o sólo puéde limitarse a imponer una elección que a*veces se opone a nuestros propios sentimientos y valoraciones morales. Bien sabemos que existen y han existido siempre formas de organización social cuya moral vigente exige anteponer los deberes para con la patria a los deberes familiares, y otras que, en cambio, anteponen éstos a aquéllos. No puedo comprender que una decisión en un sentido o en otro -y desde luego esto vale para todos los conflictos de valor-, tenga su fundamento último en la voluntad ajena, cualquiera sea ésta; ni tampoco, como algunas doctrinas éticas pretenden, en un cálculo casi matemático de sus posibles consecuencias medidas en cantidades de bienes a lograr y de males a evitar, cálculos que en rigor por lo imprevisible de las consecuencias, para uno mismo y para los demás, habría que prolóngar hasta lo infinito. Una decisión de verdadero contenidó moral en una situación como la que aquí se plantea es un problema de conciencia que sólo la propia conciencia puede y debe resolver: "

He dicho antes que estoy de acuerdo con Sartre en que no se le puede dar al joven un criterio definido para la acción. Tal vez no he sido muy riguroso al expresarme de ese modo, porque si no se le puede dar una regla de conductá tomada de las morales constituidas se le puede dar, respetando su dignidad personal y su autonomia moral, un criterio para la.acción: elige el cumplimiento del deber que para tù conciencia moral encierre el contenido más alto de valor.

Es la propia conciencia moral de la persona la que puede y debé decidir en cada situación concreta entre las actitudes que le son posibles. Frente a esos dos déberes, uno debe ser cumplido, pero no al azar, confiando en el instintó, sino porque así lo juzga su conciencia moral, porque en la singular coyuntura en la que se encuentra estima el uno como más valioso que el otro, sin negar por ello la condición positivamente valiosa del deber pospuesto. La decisión puede ser sobre manera difícil, el conflicto tremendo y angustioso, pero sin duda sólo podría darse como verdadero conflicto entre dos o más instancias objetivas que reclaman una respuesta adecuada a su valor. - En él ejemplo de Sartre, ejemplo de moral viva que no puede resolverse con fórmulas abstractas, es bien claro que si el sujeto se decide por una de 
las dos actitudes posibles es porque percibe una de ellas como moralmente más valiosa. De lo contrario, su decisión no tendría significado moral alguno $y$ 'tanto valdría lo uno como lo otro. En este caso, para la conciencia moral del joven ambos deberes encierran un contenido positivo de valor y por eso no tiene que optar entre el bien y el mal; ni, por otra parte, puede encontrar en las morales dadas una regla segura para la acción, para resolver su conflicto. Pero es su propia conciencia moral la que decide, esto es, en definitiva, su peculiar configuración axiológica, su mundo de valores, su sistema de preferencia. Es probable que en iguales circunstancias otra persona obre en sentido inverso, pero si lo hace auténticamente, quiéro decir, de acuerdo a sus valores y valoraciones objetivas, su acción será tan moralmente buena como la contraria. El perspectivismo axiológico y el sentido de la vocación personal que, como ya to he señalado en otra parte, ${ }^{13}$ tiene fundamentos objetivos, aclaran el problema. Qué es propiamente eso que llamo "vocación personal", que implica la idea de un ser y un destino que nádie puede asumir por los demás $y$, por otra parte, los muchos problemas que surgen de la posible o efectiva contraposición, que a diario vivimos, entre la conciencia moral de cada persona y las morales colectivas, no son sin duda otra historia, como dirfa Kipling, pero escapan ya a mis actuales propósitos.

RAFael Virasoro 